\title{
SIGNIFICADO DO CONCEITO SAÚDE NA PERSPECTIVA DE FAMÍLIAS EM SITUAÇÃO DE RISCO PESSOAL E SOCIAL
}

Viviane Barrere Martin*

Margareth Angelo**

MARTIN, V.B.; ANGELO, M. Significado do conceito saúde na perspectiva de famílias em situação de risco pessoal e social. Rev. latino-am.enfermagem, Ribeirão Preto, v. 6, n. 5, p. 45-51, dezembro 1998.

O estudo teve como objetivo, descrever o significado do conceito saúde na perspectiva de famílias em situação de risco pessoal e social. A análise etnográfica norteou a investigação, tendo sido a coleta de dados realizada por meio de entrevistas com famílias de crianças atendidas em um Centro Comunitário de uma comunidade de baixa renda no município de São Paulo. A análise do conteúdo das entrevistas, permitiu a identificação de 7 domínios culturais. Os resultados do estudo revelaram não apenas características relativas a conhecimentos, valores e comportamentos culturalmente relevantes para a família, no que tange ao conceito saúde, mas também possibilitou a compreensão de aspectos da organização familiar tidos como significativos no cuidado à saúde de seus membros e o papel central desempenhado pela mãe neste cuidado, na cultura estudada.

UNITERMOS: conceito de saúde, cuidado à saúde, cuidado à família, famílias de baixa renda, análise etnográfica

\section{INTRODUÇÃO}

Indicadores sociais recentes possibilitam-nos visualizar uma situação dramática de pobreza da população brasileira. No Brasil, 30\% da população ou 11 milhões de famílias encontram-se em situação de pobreza; $1 / 4$ da população infanto-juvenil pertencem a famílias indigentes; nas regiões metropolitanas, $39 \%$ das crianças e adolescentes em situação de pobreza vivem em famílias chefiadas por mulheres e $22 \%$ em famílias chefiadas por pessoas que não trabalham (GOLDANI,1994) ${ }^{7}$.

Os profissionais de saúde tem há muito reconhecido os efeitos da pobreza sobre seus clientes, representada por índices alarmantes de fome, mortalidade infantil, pessoas sem teto, para citar alguns.

A enfermagem, diante deste quadro social, em face de sua posição enquanto profissional de saúde, tem identificado a pessoa em situação de pobreza como um segmento da população, que resulta em grandes implicações para a assistência, o ensino e a pesquisa (MOCCIA \& MASON, 1986) ${ }^{10}$.

Assim, a pobreza como meio possível de vida para um número cada vez maior de pessoas e de famílias representa, do ponto de vista da saúde, uma situação de risco pessoal e social.
Neste estudo a situação de risco pessoal e social de uma família, é entendida como a situação vivida pela família em desvantagem, que lhe determina características gerais de múltiplos problemas. Segundo LYNCH \& TIEDJE (1991) ${ }^{9}$, esta denominação não pretende ser um julgamento de valor, mas descrever algumas características que são gerais nesta situação. Segundo as autoras, em geral estas famílias possuem educação e recursos monetários limitados, o que as incapacita a funcionar adequadamente na sociedade mais ampla. Além disso, continuam as autoras, tais famílias possuem características relativas a estrutura e papéis familiares, processos de comunicação familiar e socialização das crianças, que são peculiares e determinantes do risco tanto pessoal como social.

Ao longo dos últimos anos, em nosso país podemos assistir o crescente interesse e compromisso de centros de ensino e pesquisa em enfermagem na área de família (BUB, 1994; ANGELO, 1995) ${ }^{2,3}$. Tal enfoque é assumido nos termos da premissa de que à família compete o cuidado de saúde de seus membros.

No desenvolvimento de conhecimento na área de família, deparamo-nos com a situação concreta de que muitas vezes temos que nos relacionar com famílias diferentes da família na qual crescemos, do ponto de vista

\footnotetext{
* Aluna do $4^{\circ}$ ano de Enfermagem da USP - Bolsista de Iniciação Científica - CNPq

** Professora Doutora do Departamento de Enfermagem Materno Infantil e Psiquiátrica da Escola de Enfermagem da Universidade de São Paulo - Coordenadora do Projeto
} 
social, econômico e cultural. E a despeito dos melhores esforços, a frustração é uma conseqüência inevitável, devido aos irrelevantes resultados das interações enfermeiro-família.

Autores como LYNCH \& TIEDJE (1991) ${ }^{9}$, ZERWEKH (1992) ${ }^{14}$ apontam de maneira expressiva a necessidade do enfermeiro aproximar-se do referencial da família para que a comunicação seja efetiva, e a satisfação profissional atingida, indicando modelos conceituais para a intervenção com famílias em desvantagem.

Em nosso meio, ELSEN $(1994)^{6}$, refere que a prática do cuidar de famílias continua permeada por incertezas, apesar da família ter sido sempre considerada como cliente da enfermagem. Segundo a autora, faltam instrumentos precisos para abordar a família e a própria definição de saúde da família, ainda não é tida como um consenso. Neste sentido, considera que a área de enfermagem familiar está apenas iniciando, o que justifica a necessidade da utilização de instrumental teóricometodológico desenvolvido em outras áreas de saber, para uma melhor compreensão da família e melhor atuação do enfermeiro.

Um dos aspectos mais difíceis na prática com famílias, é a questão de que nem sempre a comunicação é efetiva, pelo fato de que a interação profissional, geralmente baseia-se nos valores do profissional, em contraste com a visão de mundo da família, o que gera problemas, levando o profissional a utilizar estas relações problemáticas, como base para o julgamento do comportamento da família.

A dificuldade reside basicamente nos conflitos de valores, que podem ser entendidos, numa perspectiva mais conceitual, como no processo de definição da situação, que é realizado ativamente por cada um dos elementos envolvidos na situação. Neste processo de definição, cada qual entra com uma possibilidade que the é peculiar, e que consiste em um certo conhecimento que as pessoas utilizam para definir a experiência, e agir à partir desta interpretação.

Este conhecimento utilizado pelas pessoa para interpretar a experiência e induzir o comportamento, é definido pelos antropólogos como cultura (SPRADLEY, 1980) $)^{13}$.

LEININGER $(1988)^{8}$, tem enfatizado a importância de realização de pesquisas que aprofundem o conhecimento das dimensões culturais essenciais ao cuidado de enfermagem, estabelecendo assim a interrelação entre cuidado e cultura. A autora define cultura, como sendo todos os valores, crenças, normas de comportamentos, que podem ser aprendidos, compartilhados e transmitidos por um grupo específico, e que orientam as suas formas de pensar, decidir e agir com relação ao cuidado. Estrutura social é definida pela mesma autora como sendo um processo dinâmico e de natureza interdependente de diferentes elementos estruturais ou organizacionais da sociedade, e o modo como esses elementos interatuam e funcionam. Incluem o sistema religioso, familiar, político, econômico, educacional, tecnológico e cultural, delimitados pelo contexto lingüístico e ambiental, que interferem de alguma forma nas práticas adotadas pelas pessoas.

Analisando tais considerações e retomando a situação concreta vivenciada pelos enfermeiros no processo de interagir com famílias, tendo em vista o cuidado, é evidente o vazio existente entre os valores que norteiam a definição e portanto a ação profissional e o conhecimento sobre os processos de definição desenvolvidos por famílias.

Assim, partindo dos conceitos de risco pessoal e social de famílias, de cultura e de estrutura social apresentados, considerando que tais aspectos influenciam a vida da família e a maneira como percebem e agem em relação à saúde, e inevitavelmente o processo de intervenção em saúde, motivamo-nos a compreender como a família, tida como pertencente a uma cultura caracterizada por situação de risco pessoal e social define saúde.

Neste sentido, estabelecemos como objetivo deste estudo:

- Descrever o significado do conceito saúde, na perspectiva de famílias em situação de risco pessoal e social.

\section{METODOLOGIA}

Em função do objetivo proposto, a investigação foi desenvolvida segundo um enfoque qualitativo, orientado pela análise proposta pelo método etnográfico, conforme indicado por SPRADLEY (1980) ${ }^{13}$. O método consiste em uma abordagem que possibilita verificar como as pessoas vivem em seu ambiente natural e quais crenças e valores que guiam os modos delas agirem em relação a algo. É portanto, um modo sistematizado de aprender sobre determinada cultura.

A escolha desta estratégia de análise, está pautada no fato de que ela possibilita a compreensão de pessoas, do que elas fazem, o que dizem, como se relacionam umas com as outras, quais seus costumes e crenças e sobretudo, como atribuem significado às suas experiências.

Considerando-se o limite restrito desta investigação, não se pretendeu utilizar todos os passos da etnografia, como metodologia, por ser muito ampla e fugir da proposta deste estudo, mas utilizar a questão etnográfica e os passos iniciais da análise etnográfica. 


\section{A coleta de dados}

O estudo foi realizado em uma comunidade composta por famílias em situação de risco pessoal e social, localizada no município de São Paulo, e que portanto configurou-se como a cultura foco de nossa atenção.

Os dados foram coletados por meio de entrevistas, para as quais foram convidadas as famílias de crianças atendidas pelo Centro Comunitário da referida comunidade, por meio de uma nota colocada no material da criança.

Considerando-se o aspecto de estrutura familiar peculiar de famílias com características de risco pessoal e social, não tínhamos a intenção de realizar as entrevistas com todos os membros da família. Metodologicamente este é um procedimento correto, quando se trata de investigações com famílias. Segundo DEMI \& WARREN, $(1995)^{5}$, a definição de família deve estar coerente com a população pretendida para o estudo. Nesse sentido, continuam as autoras, pesquisas com famílias de baixo poder aquisitivo e em alguns grupos culturais, cuja composição da família é muito flexível, com novos membros sendo adicionados e outros deixando a família em espaço de tempo relativamente curtos, demandam uma definição diferente de estudos realizados com famílias que possuam uma estrutura mais estável.

Assim, para fins desta investigação, seguimos a orientação metodológica das autoras, que afirmam ser possível considerar a perspectiva de um dos membros da família, como fonte de informação significativa sobre o fenômeno família. Portanto, embora o convite fosse formulado à família da criança, a entrevista seria realizada com o familiar que comparecesse e este seria considerado como a perspectiva da família.

A partir das primeiras entrevistas, começou a se definir quem seria o membro da família que nos forneceria informações sobre o conceito saúde, na perspectiva da família: as mães das crianças, que aceitaram prontamente participar do projeto, e conceder as entrevistas.

As entrevistas foram realizadas com 9 mães, tendo como questão norteadora:

\section{"O que é saúde para a senhora?"}

Com o consentimento verbal das informantes, as entrevistas foram gravadas, visando garantir o máximo de fidedignidade dos discursos.

Trabalhar com uma questão norteadora, num estudo qualitativo, não significa que apenas esta questão seja formulada pelo pesquisador. Significa que esta é a questão ponto de partida. À medida que o informante vai respondendo, o pesquisador vai procurando pistas nas suas respostas, que lhe permitam formular novas questões e assim apreender de modo compreensivo o pensamento da pessoa (ANGELO, 1996) .
Sendo esta uma questão aberta, as respostas fornecidas pelas mães trouxeram informações que elas julgavam necessárias para se fazerem entender. Muitas vezes, para explicar o entendimento que tinham do conceito saúde, elas lançavam mão de exemplos do seu cotidiano, e que eram considerados pelo pesquisador, como pistas para continuar a entrevista, buscando esclarecimentos sobre a informação fornecida. Assim, por exemplo, diante da resposta "saúde é não ter preocupação na família “, o pesquisador solicitava esclarecimento, pelo fato de que uma única frase dificilmente permite compreender o pensamento da pessoa. A tentativa de obter esclarecimento gerava nova questão, por exemplo: " me explique o que é não ter preocupação na família?", que levava a mãe a explicar quem era a família, e assim prosseguia a entrevista, até que ambos, entrevistador e informante julgassem não restar nada mais a ser dito.

\section{A análise dos dados}

Esta estratégia de coleta de dados, resultou em depoimentos, que foram submetidos à análise etnográfica conforme SPRADLEY $(1980)^{13}$. mediante uma leitura atenta do discurso, que permitiu a codificação dos dados buscando compreender o significado cultural dado pelo uso de símbolos na linguagem, onde símbolo é o objeto ou evento que se refere a algo.

As estratégias de análise compreenderam:

\section{Codificação}

As entrevistas gravadas foram transcritas na íntegra e após tal procedimento, o pesquisador passou à fase de leitura atenta dos discursos. Tal leitura visa a apreensão dos significados contidos no texto, e resulta no agrupamento de informações de significados semelhantes ou códigos. Os códigos determinam a organização dos dados, à medida em que à leitura, o pesquisador destaca certas palavras, frases, formas dos informantes pensarem e agirem. Através da codificação dos dados, buscamos compreender o significado cultural, dado pelo uso de símbolos na linguagem, onde símbolo é o objeto ou evento que se refere a algo. (ANGELO, 1996) ${ }^{3}$.

\section{Identificação de domínios culturais}

Cada código foi em seguida submetido a um procedimento de análise mais refinado, buscando a apreensão do significado contido naquele material agrupado. Este procedimento, permitiu a identificação dos domínios culturais. $\mathrm{Na}$ análise etnográfica, o domínio cultural é a primeira e mais importante unidade de análise, por conter elementos essenciais ao conhecimento cultural. 
Finalizando o processo de análise, cada domínio foi descrito, caracterizando seu significado para a cultura estudada.

Os domínios culturais identificados, constituem o significado referencial de saúde para a cultura estudada, compostos à partir dos símbolos e referências identificados.

\section{RESULTADOS}

O conteúdo verbalizado pelas mães foi codificado e o processo de análise dos códigos, permitiu a identificação de 7 domínios culturais, que são descritos conforme seu significado para as famílias da cultura estudada. Representam o conhecimento cultural, o modo como as famílias percebem, interpretam e expressam o significado sobre saúde e as relações destes com as suas vidas.

\section{Formas de definir família}

A família é definida pelas mães, considerandose em primeiro lugar a família que constituíram, ou seja, marido e filhos. Em seguida, incluem a família de origem (pai, mãe, irmãos). Outros elementos como sogros, cunhados, tios, primos, noras e comunidade, são vistos como família quando estão ligados e participam um da vida do outro, caso contrário estes mesmos elementos são percebidos como extensão familiar.

"Minha família são os meus filhos"

2. Formas de definir saúde

Saúde é definida pelas mães como completo bem estar pessoal, ou o principal para se viver:

"Tendo saúde as outras coisas se resolvem"

O conceito que elaboram de saúde é determinado pelos indicadores:

Ter condições físicas:

"É ficar livre de todos os vírus"

Ter condições psicológicas:

"É estar bem com você mesma"

"É viver em paz"

Não ter nada que possa afligir o bem-estar

"É poder comer de tudo"

É não ter nada que cause risco de vida

"É não ter nenhuma doença grave"

Ter condições econômicas e sociais para viver bem "É ter boa moradia com todos os produtos de limpeza"

"É não faltar água nunca"

\section{Ter fé}

"É ter vontade de viver"

Ter proteção divina

"É Deus quem decide se uma pessoa merece

ou não ter saúde"

\section{Formas de definir família saudável}

As mães definem família saudável, considerando não apenas a ausência de doença nos seus membros, mas sobretudo a ausência de preocupação que a doença determina para os familiares, em especial para a própria mãe.

"Família doente é preocupação"

"A doença grave traz mais preocupações"

\section{Formas de verificar a saúde da família}

A mãe é o membro que cuida da saúde da família e para tanto assume para si o papel de verificá-la em seu dia-a-dia. Para tanto, utiliza-se da observação de condições que garantam a saúde.

Assim, observa se tem o que comer

"Vejo primeiro se tem o que comer"

Depois, observa se comem bem, incluindo o que ingerem e como o fazem

"Vejo se para de comer"

Observa ainda se dormem bem, principalmente as crianças

"Vejo se tem um sono tranqüilo"

Observar as condições físicas e a condição psicológica é outro aspecto da verificação

"Vejo se não tem febre"

"Vejo se estão trabalhando"

"Vejo se tem alegria"

"Vejo se estão tristes, calados"

\section{Formas de cuidar da saúde da família}

Considerando que a família doente traz muita preocupação, cuidar da saúde da família é realizado através de medidas que previnam doenças, que segundo a percepção das mães é possibilitado por:

\section{Tentar dar uma boa alimentação}

"Saber o que pode e o que não pode comer"

Tentar dormir bem

"Dormir na hora certa"

\section{Garantir condições psicológicas}

"Não deixar o pai passar nervoso"

\section{Prevenir doenças}

"Cuidar de uma gripe para não virar outra doença" 
"Não deixar pegar no esgoto"

Ir ao médico freqüentemente

"Sempre passar no médico"

Fazer tratamento se precisar

"Tomar remédio quando precisa"

\section{Tipos de facilidades para cuidar da saúde da família}

As facilidades são percebidas pelas mães, em função de ter atendidas as suas precupações. Assim, elas são elas são consideradas como tal, em função de:

\section{Ter um atendimento rápido e eficiente}

"Prefiro usar uma coisa mais rápida como o convênio"

"Quem tem a sorte de ter um convênio está bem"

Ter serviços de saúde próximos e em condições

"Se tem remédio no posto já ajuda bastante"

Ter proteção divina

"Se Deus consentir as pessoas se curam"

7. Tipos de dificuldades para cuidar da saúde da família

As dificuldades para a mãe são definidas em função da limitação ao atendimento às suas preocupações. Neste sentido, são limites percebidos pelas mães:

Não ter médico no posto

"Dificuldade é você ficar doente, virar os quatro cantos da parede e não encontrar médico"

"O médico nunca está no posto"

$O$ posto ter atendimento ruim

"O posto não tem aquele atendimento ótimo como a gente merecia"

"O posto empurra você para outro"

Ter longa espera nas consultas

"Tem que marcar consulta para 40 dias"

"Criança doente não é atendida, tem que esperar"

$O$ acesso ser difícil

"A USP é contra-mão para ir"

"O Hospital é perto e longe ao mesmo tempo, porque não tem condução direta"

\section{DISCUSSÃO}

Compreender saúde na perspectiva do outro é um desafio. Ouvir o outro, permitir que este se mostre, representa mais do que um confronto de conceitos, mas a possibilidade de ampliá-los à partir da incorporação do saber contido no outro.

Os resultados deste estudo mostram-nos o quanto nossas definições estão incompletas, se não conseguirmos alcançar o que as famílias também tem a dizer, neste caso, sobre saúde.

Os domínios culturais identificados, permitiram apreender a representação de saúde no contexto familiar da cultura estudada. Nas suas definições, é possível compreender aspectos da vivência da saúde, que são constituintes de seu universo de interações.

A percepção de saúde como algo essencial à família, não exclusivamente como seres biológicos, mas como seres globais, reflete a importância deste conceito para o viver da família, desde o viver consigo mesmo, numa perspectiva individual e de núcleo familiar, até a interação com o contexto externo.

Em seu processo de definição, os domínios culturais mostram os reflexos decorrentes da interação entre a família e as condições sócio-econômicas desfavoráveis do contexto, que determinam aspectos de comportamentos peculiares na verificação da saúde da família, onde um indicador significativo é ver se a família tem o que comer.

Em um amplo estudo, que também buscava identificar o significado de saúde e de doença numa comunidade do interior de São Paulo, QUEIROZ (1993) ${ }^{11}$, encontra resultados semelhantes, destacando o efeito mais dramático que o estar doente produz, que é a incapacidade para trabalhar e a ameaça à subsistência familiar.

Os domínios culturais revelados pelos relatos das mães, pertencentes à população de baixa renda estudada, sobre saúde e os meios de verificar e garantir saúde da sua família, refletem não apenas seus pensamentos, mas sobretudo sua vivência do papel de zelar pela saúde daqueles que estão sob sua responsabilidade em casa.

QUEIROZ (1993) ${ }^{11}$, apresenta outro resultado semelhante ao do nosso estudo, que consiste no fato de ser a mulher, como dona de casa, a personagem principal na família no trato de questões de saúde e doença. O autor afirma também que é ela quem avalia as condições de saúde, tanto a sua própria, como a de seus filhos e toma decisões de procurar os agentes de cura considerados necessários para cada caso de doença. Segundo o autor, o pai ou chefe da família permanece distante deste assunto, principalmente porque fica a maior parte do tempo longe de casa.

Outro estudo, de ALVES et al. (1996) ${ }^{1}$, destaca igualmente a mulher no contexto familiar como responsável pelo equilíbrio no binômio saúde-doença, à medida em que toma para si o cuidado com os membros da família, seja este cuidado implícito em simples medidas higiênicas ou no estabelecimento de hábitos alimentares, 
ou na decisão de ser preciso buscar ou não ajuda. As semelhanças nos resultados desse estudo com os domínios culturais da nossa pesquisa, também são encontradas nas percepções em relação à saúde, quando esta é definida tal como é vivida, ou seja, na totalidade do homem, integrando corpo, mente, espírito e ambiente.

SMITH $(1981)^{12}$, ao se referir às várias idéias sobre a natureza de saúde, indica o modelo eudaimônico como aquele que compreende múltiplas visões do ser humano, que contempla a idéia de saúde como bem-estar geral e auto-realização. Neste sentido, aponta Maslow apud SMITH (1981) ${ }^{12}$, como um representante moderno desta concepção de saúde, à medida em que seus escritos expressam um ideal da natureza e personalidade humana, onde a melhor aspiração do ser humano é aquela direcionada para a satisfação e o completo desenvolvimento, além do que o que é desenvolvido constitui-se num potencial intrínseco, sendo a saúde uma condição de realização ou a realização deste potencial.

Pode-se dizer portanto, que cada ser humano direciona-se para alguns objetivos de modo a se auto- desenvolver e se realizar, sendo a saúde a condição que o leva a isso.

As evidências de que na família, a mãe é a principal pessoa com voz decisória, como diz QUEIROZ $(1993)^{11}$, para lidar com saúde e doença reflete aspectos da organização familiar traduzida por papéis assumidos pelos membros da família, que constituem fatores que ao afetarem a vida familiar, afetam também diretamente a qualidade de vida de seus membros.

Os resultados reforçam ainda a influência da cultura sobre a vida familiar, como indicador importante no trabalho com famílias em enfermagem, e que necessitam ser explorados, sobretudo buscando-se compreender valores, crenças e práticas em relação à saúde, como também padrões de comunicação e papéis familiares significativos para a saúde familiar.

Tal conhecimento, poderá capacitar o profissional de saúde, em especial o enfermeiro a tentar assistir o indivíduo e também a família em direção à auto-realização, condição essencial para a superação de dificuldades de uma população de risco, tanto pessoal como social.

\section{THE MEANING OF THE HEALTH CONCEPT THROUGH THE PERSPECTIVE OF FAMILIES UNDER PERSONAL AND SOCIAL RISK SITUATIONS}

The purpose of this study is to describe the meaning of heath through the perspective of families under personal and social risk situations. The ethnographic analysis based the investigation and data were collected through interviews with the low income families of children attended by a Communitary Center in São Paulo city. The analysis of the interview contents allowed the identification of 7 cultural domains. The results of this stydy show the characteristics of knowledge, values and behaviours about the health concept, that are relevant to families, enabling the understanding of the family organization, that is significant to health care of each member and also the central role carried out by mothers in the studied culture.

KEY WORDS: health concept, health care, family care, ethnographic analysis, families with low income

\section{EL SIGNIFICADO DEL CONCEPTO SALUD EN LA PERSPECTIVA DE FAMILIAS EN SITUACIÓN DE RIESGO PERSONAL Y SOCIAL}

El estudio tuvo como objetivo, describir el significado del concepto salud en la perspectiva de familias en situación de riesgo personal y social. El análisis etnográfico orientó la investigación, la colecta de datos fue realizada por medio de entrevistas con familias de niños atendidos en un Centro Comunitário de una comunidad de bajos ingresos en la ciudad de São Paulo. Los análisis del estudio revelaron no sólo características relativas a conocimientos, valores y comportamientos culturalmente relevantes para la familia, en lo que corresponde al concepto de salud, sino que también posibilitaron la comprensión, aspectos de la organización familiar, tenidos como significativos en el cuidado de la salud de sus miembros y el papel central ejercido por la madre en ese cuidado, en la cultura estudiada.

TÉRMINOS CLAVES: concepto de salud, cuidado de la salud, cuidado de la familia, análisis etnográfico, familias de bajo ingreso

\section{REFERÊNCIAS BIBLIOGRÁFICAS}

01. ALVES, A.R. et al. Saúde e doença: uma abordagem socio-cultural. In: FLORES e SILVA, FRANCO. Saúde e doença: uma abordagem cultural da enfermagem. Florianópolis: Papa-Livro, 1996. cap.3, p.56-74.
02. ANGELO, M. A família como foco do cuidar. São

Paulo: EEUSP, 1995 (mimeografado).

03. ANGELO, M. Análise de dados qualitativos. São Paulo: EEUSP, 1996 (mimeografado). 
04. BUB, L. (coordenadora) Marcos para a prática de enfermagem com famílias. Florianópolis. Ed. da UFSC, 1994,195p.

05. DEMI, A.S.; WARREN, N.A. Issues in conducting research with vulnerable families. West. J.Nurs. Res., n.12,v.2, p.188-202, 1995.

06. ELSEN, I. Desafios da enfermagem no cuidado da família. In: BUB,L.(coord.). Marcos para a prática de enfermagem com famílias. Florianópolis: Ed. da UFSC, 1994. cap.2, p.6177.

07. GOLDANI, A.M. As famílias brasileiras: mudanças e perspectivas. Cad.Pesq., n.91, p.7-22, 1994.

08. LEININGER, M.M. Leininger's theory of nursing: cultural care diversity and universality. Nurs.Sci., v.1, n.4, p.152-160, 1988.
09. LYNCH, I.; TIEDJE, L.B. Working with multiproblem families: an intervention model for community health nurses. Public Health Nurs. v.8, n.3, p.147-153, 1991.

10. MOCCIA, P; MASON, D.J. Poverty trends: implications for nursing. Nurs.Outlook, v.6, n.4, p.197-203, 1986.

11. QUEIROZ, M.S. Estratégias de consumo em saúde entre famílias trabalhadoras. Cad. Saúde Pública, v.9, n.3, p.272- 282, 1993.

12. SMITH, J.A. The idea of health: a philosophical inquiry. Adv.Nurs.Sci., p.43-50,1981.

13. SPRADLEY, J.R. Participant observation. New York: Wolt,Rinehart and Winston, 1980. 195p.

14. ZERWEKH, J.V. Laying the groundwork for families, building trust, and building strength. Public Health Nurs. v.9, n.1, p.15-21, 1992. 